\title{
Experiências formativas do Pibid em uma universidade pública: movimentos de integração com a escola
}

\section{Amanda Regina Gonçalves}

\begin{abstract}
MARTINS, Rosa Elisabete Militz Wypyczynski; ROSSATO, Luciana (Org.). Reflexões sobre as experiências do Pibid na Udesc. Santa Cruz do Sul, SC: Edunisc, 2015. 251 p.
\end{abstract}

A coletânea Reflexões sobre as experiências do Pibid na Udesc foi organizada

por Rosa Elisabete M. W. Martins e Luciana Rossato, professoras nos cursos de licenciatura e, respectivamente, coordenadoras de área dos subprojetos de geografia e história do Programa Institucional de Bolsa de Iniciação à Docência (Pibid) na Universidade do Estado de Santa Catarina (Udesc), em Florianópolis.

A publicação traz treze textos, escritos por professores coordenadores de subprojetos e da equipe de gestão do Pibid-Udesc, que tratam de trabalhos desenvolvidos em contextos escolares, fomentando a aproximação entre a formação acadêmica e as situações práticas vivenciadas nas escolas. Este livro representa um movimento de produção de conhecimento específico do período atual nas licenciaturas brasileiras, cuja particularidade se define pela implantação e primeiros resultados, sobretudo quanto à promoção da integração entre a universidade e a educação básica, de um programa de formação de professores para a educação básica implantado pela Coordenação de Aperfeiçoamento de Pessoal de Nível Superior (Capes), fundação vinculada ao Ministério da Educação (MEC). Tradicionalmente a Capes "desempenha papel fundamental na expansão e consolidação da pósgraduação stricto sensu (mestrado e doutorado) em todos os estados da Federação", mas, a partir de 2007, por meio do Pibid, passou também a atuar na formação de professores da educação básica.

O Pibid é evidenciado como parte de avanços nas políticas públicas atuais direcionadas à formação de professores no Brasil, com impacto forte nos cursos de licenciatura. Os relatos de experiência são tomados como importantes, pois 
fomentam a aproximação do mundo teórico, inerente à formação acadêmica, com as situações práticas vivenciadas na sala de aula das escolas.

O primeiro capítulo, "Por uma educa-ação plena: a Udesc e o Pibid", de Sandra Makowiecky, auxilia o leitor a entender os desafios enfrentados na implantação do Pibid nessa universidade e que também foram comuns a muitas outras, especialmente para aquelas que apresentam um contexto de expansão, sobretudo de licenciaturas, no qual não é valorizada a formação de professores. Entre os principais desafios, destacam-se o de consolidar uma nova cultura de formação docente centrada na relação teoria/prática, e o de enfrentar as desarticulações entre educação superior e educação básica.

No capítulo "Pibid Geografia da Faed/Udesc: experimentações na iniciação à docência", Rosa Elisabete M. W. Martins discute como modelos de escola vigentes carecem de identificar que o saber escolar não é o acadêmico, nem uma simplificação deste, mas sim uma forma particular de conhecimento, que exige novos olhares para reinventar a escola. Experiências como monitorias, oficinas com o uso de literatura no ensino de geografia, projeto de organização de jornal escolar e trabalhos de campo no centro da cidade são relatadas pela autora, que destaca a importância dessas atividades para a compreensão da organização e do funcionamento da escola. Elas também promoveram o fortalecimento da prática investigativa, enquanto compromisso com a profissionalização do professor e com a produção de saberes pedagógicos que dialoguem com as problemáticas educacionais e da ciência geográfica.

No terceiro capítulo, "Tornar-se professor de história: a experiência como bolsista Pibid", Luciana Rossato e Núria A. S. de Oliveira trazem representações de licenciados egressos do Pibid-História presentes em memoriais escritos por eles sobre a participação e as contribuições do projeto para a formação docente e o ensino de história. Dentre elas, destaca-se a realização do projeto "Cine-história", com o objetivo de abordar conflitos, preconceitos e violência no espaço escolar. Desse projeto resultaram duas contribuições para a formação do licenciando: trabalhar com questões referentes à discriminação étnico-racial, social, de sexo e de gênero, por meio dos debates provocados pelos filmes selecionados, e produzir um vídeo, que os levou a conhecer e manipular programas de edição de imagens.

O quarto capítulo, intitulado "O Pibid e suas repercussões na formação docente para os anos iniciais do ensino fundamental", foi escrito pelos coordenadores de área do subprojeto de pedagogia do Pibid-Udesc, Alba R. B. de Souza e Lourival J. Martins Filho, que, apoiados em António Nóvoa (2009), discutem sobre o "abismo" acadêmico, caracterizado pelo fato de instituições de formação de professores ignorarem ou conhecerem mal a realidade das escolas. A análise dos dados, obtidos pelos questionários aplicados a dez bolsistas de iniciação à docência do curso de pedagogia sobre as principais aprendizagens que o programa lhes proporcionara, revelou que o Pibid é percebido como uma importante iniciativa na construção de novas possibilidades de formação docente vinculada às demandas da educação básica, na integração escola e universidade, na valorização da carreira de professor e na conquista da profissionalidade docente. Os autores concluem que a formação 
da identidade e a profissionalização docente necessitam de uma maior integração entre as demandas da educação básica e a formação inicial do professor, sendo uma responsabilidade de diversos segmentos, como universidades, agências de fomento, sistemas de ensino e gestores.

No quinto capítulo, "Relato de experiências com uma horta agroecológica no ensino de geografia: sabores e saberes na educação básica", Marina C. R. e Silva, Mariama B. Bacci e Ana Maria Hoepers Preve apontam que a horta é considerada um clichê da educação ambiental devido ao fato de muitos trabalhos reproduzirem dela uma imagem sem concebê-la de forma crítica, deixando que, muitas vezes, funcione a partir de um sistema normativo, sem reflexão sobre os porquês daquela ação. Para superar o clichê, é necessário saber que ele existe e a abordagem agroecológica é indicada como bastante dinâmica e prática para a construção coletiva de uma horta no espaço escolar. As autoras relatam que dela colheram alimentos, experiências, saberes, carinho, paciência, cooperação e reflexão, além de emergirem, dali, diversos minicursos, aulas práticas, trabalhos de conclusão de curso e de mestrado. Entre as atividades realizadas, destaca-se o cultivo de alimentos orgânicos contraposto ao de alimentos com agrotóxicos, pois o primeiro não usa agentes tóxicos poluidores e propõe técnicas e métodos sustentáveis de produção de alimentos. Essa abordagem permite, ainda, o desenvolvimento de agroecossistemas que têm por princípios a geração da biodiversidade, o respeito a todas as formas de vida, à saúde e à segurança alimentar, os policultivos, a reciclagem de matéria orgânica. Os participantes também realizaram expressões artísticas nas paredes da horta, reconhecimento de plantas medicinais, brincadeiras e produção de mudas. O projeto nomeado "Espaço Coletivo Bicho Urbano" teve início em 2012 por meio do Pibid e estava no seu terceiro ano de funcionamento.

No sexto capítulo, "O teatro e o projeto Pibid da Udesc: breve panorama dos desafios da formação do artista docente", Vicente Concilio apresenta a integração dos estudantes da licenciatura em teatro ao contexto da educação básica, dada, primeiramente, pela participação dos licenciandos em reuniões pedagógicas, reuniões de Conselho Escolar, reuniões com pais e responsáveis, entre outras atividades realizadas em uma escola parceira do subprojeto. Ao mesmo tempo, foi proposta uma ampliação das atividades curriculares em teatro para espaços escolares, construindo novos lugares de prática teatral oferecidos pela escola, como pátios, corredores e quadras. São destacados estudos e atividades que utilizavam o jogo dramático como aliado na exploração de possibilidades expressivas e corporais dos alunos, como a disponibilidade para improvisar, a ampliação do repertório vocabular e gestual, a capacidade de criação e integração a projetos coletivos, o desenvolvimento da escuta aos parceiros e à plateia, a apreciação de outras linguagens artísticas além do teatro. O autor conclui que essas atividades fazem parte do objetivo de reforçar a prática do ensino de teatro nas escolas a partir do próprio fortalecimento da formação inicial do professor e observa que a qualidade das experiências na escola pública é um fator que pode, em médio prazo, mudar o panorama atual que reflete pouca presença da linguagem teatral nas escolas. 
No sétimo capítulo, intitulado "Pibid Educação Física: aprender a ser professor na docência", Gelcemar O. Farias, Marília G. Pinto, Adriana Werner e Alexandra Folle discutem as atividades inseridas no Pibid como oportunidades de relação entre a formação teórica e a familiarização com a realidade, dinamizando a formação dos licenciandos e a compreensão da cultura docente. São apresentadas três ações ocorridas no ano de 2014 em uma escola municipal de Florianópolis: o desenvolvimento de mural temático sobre a Copa do Mundo, a produção de um jornal escolar e o desenvolvimento de práticas e reflexões por meio do esporte e de jogos culturais. O "Mural da Copa Pibid" buscou mobilizar os alunos da escola como um cenário representativo dos conteúdos da disciplina de educação física e outras áreas. Nele foram inseridas questões históricas sobre os dois momentos em que a copa aconteceu no Brasil (1950 e 2014), as seleções, os estádios de futebol, as localizações geográficas, as bandeiras e as notícias que marcaram época. Essas ações foram concomitantes ao desenvolvimento de aulas, nas quais foram estudadas questões sociais, políticas e esportivas. Durante os jogos da Copa, os alunos da escola complementavam o mural com os resultados diários dos jogos e informações sobre o evento no Brasil. Já a ação de elaboração de um jornal escolar foi um trabalho interdisciplinar de turmas de alunos envolvidas no Pibid de educação física com as professoras de português, ciências e informática e a direção da escola. Em reuniões semanais foram definidos e desenvolvidos: o nome e o logo do jornal, o layout, as seções e seus conteúdos (Capa, Coluna do Professor, Clubinho de Ciências, Coluna do Aluno, Coluna do Aluno Repórter e Notícias da Escola). A terceira ação, que promoveu os jogos culturais na escola, partiu de práticas esportivas e recreativas em formato de gincanas (corrida de perna de pau, corrida do saco, chinelão, cabo de guerra, desafios organizados em tarefas) que buscavam desenvolver a mobilização dos estudantes no que diz respeito a autonomia, organização, solidariedade, responsabilidade, tolerância, fraternidade, compreensão e a promoção do exercício da cidadania. Os autores concluíram que tais ações dinamizaram a formação inicial dos licenciandos, destacando-se a permanência dos bolsistas ao longo dos projetos, pois tal inserção prolongada possibilita a aquisição de habilidades e competências que favorecem o conhecimento in loco da futura profissão, e também a intersecção entre a professora supervisora e os bolsistas, promovendo a socialização de saberes e deflagrando a sensibilidade da formação docente, ao mesmo tempo em que consolida as emergentes necessidades da escola e o conhecimento da realidade.

No oitavo capítulo, "Artes visuais como experiência: entre cultura visual e paisagem", Jociele Lampert trata de reflexões sobre o campo de estudo da cultura visual e suas aproximações com a diversidade do mundo das imagens, das representações visuais, dos processos de visualização e de modelos de visualidade, nos quais a arte se torna produção cultural. Inicialmente, os licenciandos desenvolveram trabalhos de campo no bairro da escola para buscar o entendimento da cultura visual do entorno da escola, com o objetivo de pesquisar as visualidades presentes no cotidiano daquela região, além de buscar tessituras sobre o contato com a comunidade, especialmente junto aos alunos da escola e seus locais de moradia. Em outra escola, o trabalho fundamentou-se em estudos que relacionavam paisagem 
e artes visuais, principalmente em obras de artistas que os alunos viam em museus, igrejas e galerias de arte da cidade. Conclui que, para ser um professor artista, é necessário que a pesquisa seja inerente ao processo de criação, e que se pondere sobre o lugar/espaço/tempo de produção e recepção do "objeto" artístico.

No capítulo nono, intitulado "Aquecimento global: construindo uma ilha de racionalidade como prática interdisciplinar no ensino de física", Ivani Lawal, Tatiane Floes e Karlinne Devegili apresentam as etapas de modelos interdisciplinares para representar situações cotidianas, com base na Ilha Interdisciplinar de Racionalidade, proposta por Gérard Fourez (2002), que a define como sendo uma intervenção de uma modelização adequada para uma situação específica. Essa metodologia permite que o estudante se expresse e se posicione diante de assuntos relacionados ao seu cotidiano, com responsabilidade, desenvolvendo certa autonomia e uma linguagem científica adequada. A atividade foi executada em cinco etapas: apresentação da proposta e de uma "carta problema" contendo uma descrição da problemática do aquecimento global e uma pergunta sobre como evitá-lo; panorama das questões e divisão dos grupos de trabalho; pesquisa e trabalho de campo; esquema geral da situação; e síntese do trabalho. Os autores concluíram que a Ilha Interdisciplinar de Racionalidade é uma estratégia de trabalho escolar que desenvolve a autonomia de pesquisa nos estudantes e a linguagem científica, além de promover uma atividade interdisciplinar.

Descrevendo os caminhos percorridos pelos bolsistas, no décimo capítulo, "Vivências do subprojeto Pibid da licenciatura em matemática da Udesc", Regina H. Munhoz, Ivanete Z. Siple e Marnei L. Mandler apresentam a sequência de algumas atividades. Iniciam pelos estudos de referencial teórico, a exemplo do livro "O laboratório de ensino de matemática na formação de professores" (Lorenzato, 2006), estudado no subprojeto quando da implementação de um laboratório de educação matemática na escola pelo subprojeto do Pibid. Também citam o desenvolvimento de um projeto de reforço de ensino denominado Clube de Matemática; a elaboração e realização de uma gincana, a Gincanamática, para incentivar o trabalho em equipe e o desenvolvimento do raciocínio lógico; confecção e aplicação de jogos educativos e de roteiros de atividades interdisciplinares; confecção de fichas sobre matemáticos que são referências históricas para a ciência; oficinas de matemática com o uso do software livre Geogebra; estudos sobre história e cálculos sobre os impostos. Por fim, apresentam dados sobre os licenciados egressos desse subprojeto do Pibid, evidenciando, nas ações posteriores, fatos relacionados à educação matemática e às atividades desenvolvidas no Pibid, como o aprofundamento de pesquisas sobre as atividades do Pibid em trabalhos de conclusão de curso; divulgação e publicação dos trabalhos em eventos de educação e educação matemática; e o fato de quase metade deles estar atuando na docência na educação básica, outros continuando os estudos em cursos de mestrado na área de educação matemática e ensino de ciências, e uma licenciada atuando como professora na própria universidade.

No décimo primeiro capítulo, "Atividades desenvolvidas no primeiro projeto do Pibid Química-Udesc", Maria da Graça M. B. Martin e Fabíola C. Viel tratam da práxis como fundamento que permite desenvolver as capacidades do pensamento por meio do relacionamento dialético com as atividades de ensino realizadas na escola. Entre as atividades realizadas no subprojeto de química na escola, 
destacam-se a construção e o funcionamento de um biodigestor, a confecção de um painel dos elementos da tabela periódica, e a organização de uma feira de ciências na escola. As autoras ressaltam que há licenciados egressos desse subprojeto que atuam na rede pública de ensino ou são mestrandos na área de educação.

No décimo segundo capítulo, "Materiais educativos de inclusão: perspectivas interdisciplinares", Maria Cristina Fonseca Silva, Regina F. Schambeck e Eloísa C. Gonzaga apresentam ações desenvolvidas na escola junto a alunos com necessidades especiais, por exemplo, no setor de Atendimento Educacional Especializado (AEE), com o objetivo de demonstrar a importância do trabalho coletivo e interdisciplinar na escola para a educação inclusiva. As ações iniciaram-se com a observação e a problematização da realidade escolar, seguidas de proposições alternativas de intervenção na escola e diagnóstico das práticas inclusivas nas salas de aula. Também se destacaram os estudos para se construir o conceito de interdisciplinaridade entre os membros do grupo. O texto traz perspectivas históricas do jogo e do brincar e experiências de produção de jogos (jogo da face, dominó musical, jogo viajante, quebra-cabeça musical, rota portuguesa, entre outros) por meio de atitudes interdisciplinares preocupadas com processos de inclusão de alunos com necessidades especiais.

No último capítulo, "A performance musical na formação de pensamento crítico: uma experiência no subprojeto da área de música", Vânia B. Müller, Arthur Boscato e Pedro Henrique de O. da Silva mostram como atividades musicais em sala de aula - por exemplo, oficinas de violão e outros instrumentos -, podem ser oportunidades de exercício da autonomia responsável, por meio de uma abordagem crítica e politizada na formação de futuros educadores musicais. Os autores descrevem a criação e desenvolvimento da Companhia Musicar nas escolas parceiras do Pibid, a organização de recitais didáticos e a apropriação de objetos sonoros alternativos como formas de intervir na naturalização do status quo social, político e cultural por meio da música.

As escritas que compõem esta coletânea valem-se das potencialidades da experiência narrativa, tal como exposto no prefácio, por Ivaine Maria Tonini, que chama a atenção para os relatos das atividades desenvolvidas nos vários subprojetos como produções que evidenciam a interação entre saberes e fazeres a partir das experiências, e, muitas delas, impactam as condições de aprendentes e ensinantes no processo da docência. Apoiando-se em Jorge Larrosa Bondía (2014), ela afirma que, para que as possibilidades sejam experiências, estas devem ser tomadas para transformar o que está ali proposto e não para executar o que está ali planejado.

As atividades desenvolvidas nas escolas por meio dos subprojetos do Pibid de distintas áreas evidenciam significativos impactos na formação dos licenciandos para sua atuação como futuros professores. Trata-se de um programa recente, cujo funcionamento nas universidade e escolas está em processo de consolidação. Seus avanços e melhorias começam a ser detectados e os ajustes, analisados.

Os autores são unânimes em reconhecerem a importância do Pibid para a melhoria da qualidade da formação inicial de professores nos cursos de licenciatura, para a promoção da integração entre a universidade e a educação básica e para a valorização do magistério. O leitor passa a compreender como experiências de planejamento, ensino e reflexão desenvolvidas no âmbito do Pibid podem proporcionar esses avanços. 


\section{Referências bibliográficas}

BRASIL. Coordenação de Aperfeiçoamento de Pessoal de Nível Superior (Capes). História e missão. 2008. Disponível em: <www.capes.gov.br/historia-e-missao> . Acesso em: 20 dez. 2016.

BRASIL. Coordenação de Aperfeiçoamento de Pessoal de Nível Superior (Capes). Portaria Normativa Capes no 122, de 16 de setembro de 2009. Dispõe sobre o PIBID - Programa Institucional de Bolsa de Iniciação à Docência, no âmbito da CAPES. Disponível em: < http://www.capes.gov.br/images/stories/download/bolsas/ PortariaNormativa122_PIBID.pdf>. Acesso em: 3 mar. 2017.

BRASIL. Coordenação de Aperfeiçoamento de Pessoal de Nível Superior (Capes). Portaria $n^{\circ} 46$, de 11 de abril de 2016. Aprova o regulamento do Programa Institucional de Bolsa de Iniciação à Docência - Pibid. 2016. Disponível em: $<$ https://www.capes.gov.br/images/stories/download/legislacao/15042016Portaria-46-Regulamento-PIBID-completa.pdf $>$.

BRASIL. Decreto n 6.755, de 29 de janeiro de 2009. Institui a Política Nacional de Formação de Profissionais do Magistério da Educação Básica, disciplina a atuação da Coordenação de Aperfeiçoamento de Pessoal de Nível Superior CAPES no fomento a programas de formação inicial l e continuada, e dá outras providências. Diário Oficial da União, Brasília, DF, 30 jan. 2009. Revogado pelo Decreto $n^{\circ} 8.752 / 2016$.

FOUREZ, Gérard. Crise no ensino de ciências? Investigação em Ensino de Ciências, Porto Alegre, v. 8, n. 2, p. 1-15, 2003.

LARROSA BONDÍA, Jorge. Tremores: escritos sobre experiência. Belo Horizonte: Autêntica, 2014.

LORENZATO, Sérgio. O laboratório de ensino de matemática na formação de professores. Campinas: Autores Associados, 2006.

NÓVOA, António. Professores: imagens do futuro presente. Lisboa: Educa, 2009.

Amanda Regina Gonçalves, doutora em Geografia pela Unesp (Rio Claro), é professora adjunta do Departamento de Geografia da Universidade Federal do Triângulo Mineiro (UFTM), Uberaba-MG, coordenadora do Laboratório de Educação Geográfica (Labeduc-Geo) e do Grupo de Estudos e Pesquisa "Rapsódia: Educação, Geografia e Cultura".

goncalves.amanda@gmail.com 